\title{
Robust E-Health Communication Architecture for Rural Communities in Developing Countries
}

\author{
Francis Idachaba \\ Dpt of Electrical and Information Engineering \\ Covenant University Ota \\ Nigeria \\ idachabafe@yahoo.com
}

\author{
Ejura Idachaba \\ Covenant University Health Center \\ Covenant University Ota \\ Nigeria. \\ idachabaejura@yahoo.com
}

\begin{abstract}
The lack of access to quality healthcare and the lack of sufficient manpower, especially doctors, in rural areas is a major healthcare challenge faced by dwellers in rural communities in most developing countries. The intervention of governments, which range from the introduction of training programs aimed at producing health workers from schools of health technology and nursing to the recalling and deployment of retired nurses to rural areas, has still not been able to generate the desired improvement in healthcare delivery, as outbreaks of epidemics are still being reported in such areas. This work presents an E-Health architecture which utilizes low cost sensors and communication devices to link the doctors in the urban areas with the patients in rural areas enabling doctors-patients interaction. The system enables accurate and timely diagnosis of the patients and facilitates proper treatment plans. It also incorporates an epidemic alert which enables the tracking of diseases and the early detection and control of epidemics.
\end{abstract}

Keywords- doctors; e-health; epidemic; rural areas; vital signs

\section{INTRODUCTION}

The current healthcare challenges faced by developing nations especially in the African continent is deepened by the lack of sufficient manpower, especially doctors, and this is felt the most in rural areas. Uneven distribution of health personnel is judged to be a greater problem than actual shortage of supply. The concentration of a high percentage of personnel in large cities depletes services to rural areas [1]. Medical schools keep producing doctors yearly, but these doctors are reluctant to go to rural areas due to the challenges associated with such areas $[2,3]$. Nigeria has one of the largest stocks of human resources for health (HRH) in Africa: 28 doctors (as at 2007, currently 40) and 170 nurses per 100,000 population. This compares with a sub-Saharan average of 15 doctors and 72 nurses per 100,000 population. Despite the large stock of HRH, there are great disparities in health status and access to health care among different population groups in Nigeria. For example, the under-five mortality rate in rural areas is estimated at 243 per 1,000 live births, compared with 153 per
1,000 in urban areas. While $59 \%$ of women in urban areas deliver with a doctor, nurse, or midwife, only 26 percent of women in rural areas do so [4]. The HRH assessment indicated that the major reason for the great disparities in health status and access to health care among different population groups in the country is the misdistribution of health workers [4]. The government, over the years, has introduced training programs aimed at producing more low level medical and health workers from schools of health technology and schools of nursing. Retired nurses are currently being recalled from retirement and sent to rural communities to improve the health care delivery. These strategies, however, have still not been able to generate appreciable improvement in health care delivery as outbreaks of epidemics in remote areas are still being recorded [5-12]. This gap in the healthcare service delivery due to the inadequate number of healthcare personnel often leads to the problem of quackery as quacks and charlatans rise up to provide alternatives which, in most cases, result in unaccounted fatalities. The current shortages in health workers and especially doctors is most acute in sub-Saharan Africa which is home to the $11 \%$ of the world's population and accounts for $24 \%$ of the global disease burden but has only $3 \%$ of the world's health workers [13, 14]. This paper presents an EHealth architecture [15] which will enable doctors in urban areas to interact with patients in rural areas. The system also incorporates an epidemic alert which will enable the tracking of diseases and the early detection and control of epidemics.

\section{METHODOLOGY}

The system utilizes sensors to capture the vital signs of the patients. These signs include patient's weight, height, temperature and blood pressure. The data is digitized and sent as an electronic mail through the communication network to the doctor in the urban hospital. The system utilizes audio/visual equipment to provide both audio and video feed in order to enable doctors to have both audio and visual interaction with patients. An onsite health attendant manages the health center and provides language translation between the 
doctor and the patient and also performs physical examination under the guidance of the doctor. The doctor's prescription is sent to the remote health center and printed out for the patient for onward transmission to the pharmacy. This architecture provides to rural dwellers an access to high-quality medical expertise available in the cities, without demanding them to physically be there, except in extreme cases.

\section{TECHNOLOGY DESCRIPTION}

From the system architecture in Figure 1, each village or hamlet is provided with a health center manned by the onsite health attendant. A number of health centers transmit to one collation center. The collation center collates the transmissions from the health centers and transmits the data via satellite to the doctor in the urban area. The doctor, upon receipt of the patient's details, commences the interactions with the patient. These interactions (both audio and video) are stored on the doctor's end. Only the final prescriptions are sent back to the health center for printing and delivery to the patient.

\section{A. Transmission between Collation center and Hospital in Urban Area}

Video communications has high quality of service (QoS), high bit rate and hence high bandwidth demands [16, 17]. In video transmissions, the transmission paths and the receivers have different capacities and multilayer transmission is used to solve the problem of varying bandwidth in multimedia multicast applications. A multilayered video encoder compresses a raw video sequence into one or more streams or layers with different priorities. The highest priority layer is called the base layer as it contains the most important data of the video while the other layers are called enhancement layers as they contain refinements of the base layer [18]. When a network link is congested, the lower priority packets get discarded. A number of compression algorithms are currently in use, the most popular being the MPEG2, MPEG4 and the Motion JPEG 2000(MJ2). The MJ2 utilizes JPEG2000 for the compression, in order to generate frame by frame independent code streams. The absence of inter frame dependencies as used in MPEG2 and MPEG4 reduces the processing complexities of the compression process [16]. To achieve an optimum video quality during high error rates, a robust and error rate adaptive link layer transport is required and, thus, the second generation Digital Video Broadcast (DVB-S2) [19] has been adopted as the satellite link layer transport mechanism. It offers enhanced error protection and flexible input data stream format. Using adaptive coding and modulation enables the operation within a carrier to noise ratio of $-2.4 \mathrm{~dB}$ to $+16 \mathrm{~dB}$. During high link error, the data field length (DFL) in each physical frame is reduced to allow more FEC codes. The DVB-S2 is optimized for High Definition TV, news gathering and interactive services [20]. The DVB-S2 modem is combined with encoders and multiplexers, as shown in Figure 2, to allow the transmission of multiple streams of signals from the health centers onto one carrier frequency for transmission through the satellite to the hospital in the urban area and back to the rural area.

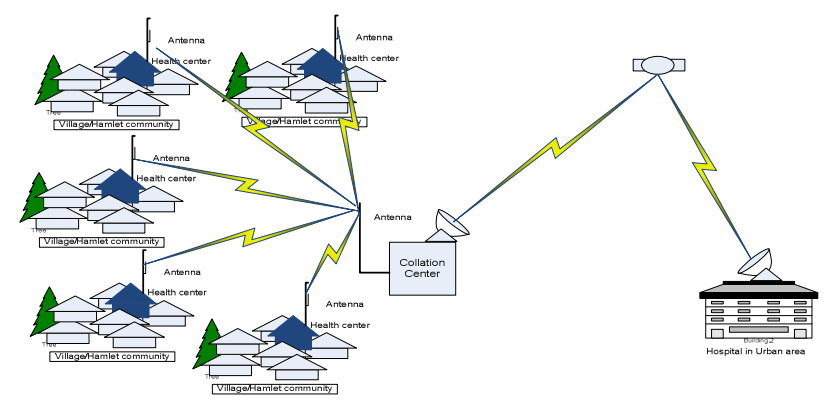

Fig. 1. System Architecture

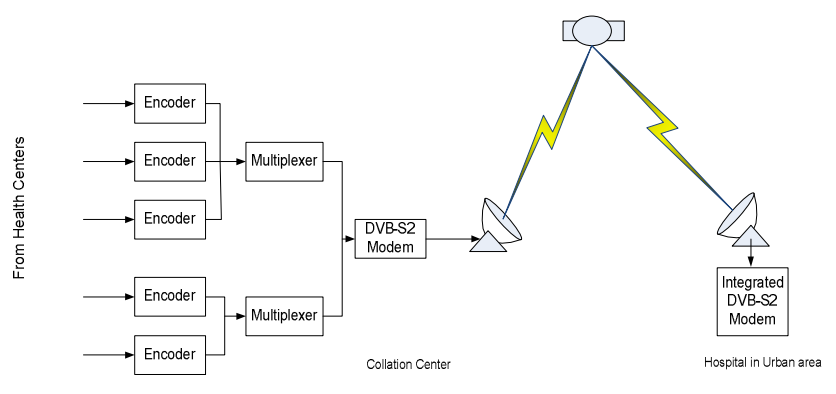

Fig. 2. Transmission diagram from village health centers to collation center

\section{B. Point to point link between the Health Center and the Collation Center}

Point-to-point digital microwave radio (DMR) is a digital transmission technology that provides a wireless radio link operating at microwave frequencies between two points. A terminal at one end of the link communicates exclusively with a complementary terminal at the other end of the link. Each terminal is fitted to a parabolic dish antenna and communication is by line-of-sight beams between the dishes. Communication distances can be as short as a few meters (e.g. across the street between city buildings) or very long (up to $80 \mathrm{~km}$ ) in the country. To achieve line-of-sight, the antennas are typically mounted on rooftops, on hills or on towers. Links can also be daisy-chained to avoid major obstructions or to cover virtually endless communications distances. DMR links can be used to carry a wide variety of traffic [21].

\section{The health center}

The block diagram of the health center is shown in Figure 3. It comprises of the following:

1. Digital sensors for taking patients vital signs: These sensors include weight and height sensors, sphygmomanometers for blood pressure measurement and thermometers for temperature measurement. These sensors can be linked to the computer system either using wires or wirelessly (using Bluetooth). However the manual methods of data capture can still be used with the onsite attendant taking the readings and inputting them into the computer system for the transmission to the doctor. 
2. Audio visual equipment: This equipment includes a camera and a microphone/ speaker system. They are used for the doctor-patient interactions.

3. Computer system: The computer system collates all the sensor data. The onsite attendant ensures that the patients are properly positioned for the data to be captured. It serves as the gateway by linking the health center to the doctor and managing the two way communication between the doctor and the health center.

4. Power supply: The power supply for the health center is based on renewable energy. Solar and wind energy coupled with back up batteries are used to provide electric energy for the health center. The choice between solar or the wind is determined by the availability of each source in the rural location. The sensors (data capture devices) are individually powered by rechargeable batteries which can be recharged in the health center.

The onsite health attendant will be required to be able to communicate in the local languages of the area and will be required to populate the patient's information sheet and forward the same to the doctor before the video sessions commence. The digital video signal is compressed using an MPEG software encoder, and then wrapped in an IP packet for transmission [22] as shown in Figure 4.

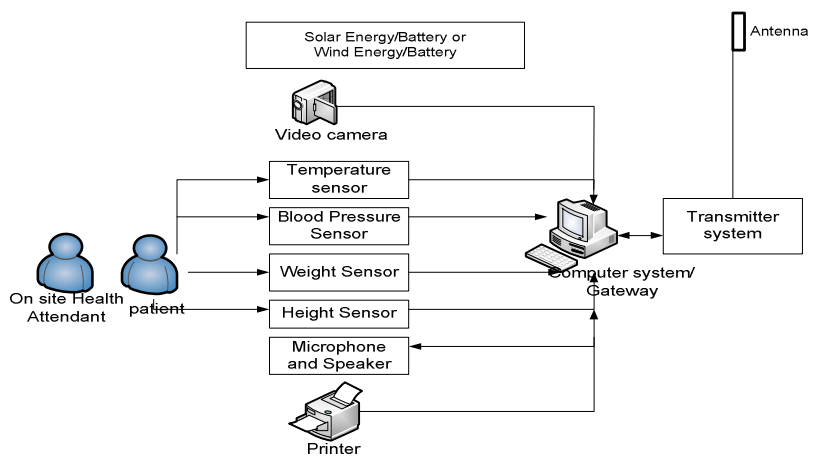

Fig. 3. Block diagram of the health center

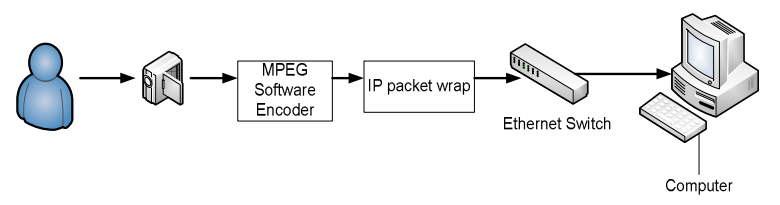

Fig. 4. Video compression and packaging for transmission.

The video sessions can be implemented using any video stream management software, an example being the Cisco stream manager video surveillance solutions [23]. The video surveillance provides real-time monitoring and observation of the patient by the doctor in the urban center hospital and it also enables the doctor to guide the onsite health attendant to perform any physical examination required. It also provides a recording of the sessions in the event that there is a need for second opinions in serious cases. The recording and documentations, however, are subject to the doctor-patient confidentiality and can only be transferred with the patient's consent.

The microwave link can be implemented by a wide variety of available equipment. The generic equipment lists include an indoor unit, an outdoor unit, two antennas, surge protectors, grounding kits and cables. Typical power consumptions of the equipment in the health center are listed in Table 1.

TABLE I. TYPICAL HEALTH CENTER EQUIPMENT AND POWER CONSUMPTION.

\begin{tabular}{|c|c|c|}
\hline Equipment & Use & $\begin{array}{c}\text { Typical Power } \\
\text { consumption values }\end{array}$ \\
\hline Thermometer & \multirow{4}{*}{ Vital signs } & \multirow{4}{*}{ Nil } \\
\hline Sphygmomanometer & & \\
\hline Weigh scale & & \\
\hline Meter rule & & \\
\hline Desktop computer system & \multirow[b]{2}{*}{ Communication } & $50 \mathrm{~W}$ \\
\hline $\begin{array}{l}\text { Microwave Transmission } \\
\text { system }\end{array}$ & & $100 \mathrm{~W}$ \\
\hline Antennas & \multirow{3}{*}{ Communication } & Nil \\
\hline Web camera & & Nil \\
\hline Ethernet switch & & $20 \mathrm{~W}$ \\
\hline Surge protectors & Protective devices & Nil \\
\hline $\begin{array}{l}\text { Solar panels, Inverter and } \\
\text { deep cycle batteries }\end{array}$ & Power supply & \\
\hline
\end{tabular}

As shown in Table 1, the power consumption is below 200W and solar power supplies capable of generating in excess of $500 \mathrm{~W}$ are readily available. The OPEX of the system is very low due to the use of renewable energy. Such equipment is readily available in the market and can be set up by anyone with basic IT training in Networking, VSAT installation, expertises also readily available. The doctors and onsite health attendants given basic computer appreciation courses can comfortably and efficiently utilize the system

\section{RESULTS}

The main results generated by this system includes the diagnosis and prescription from the doctors in the urban areas for patients in the rural areas which results in better treatment plans for these patients. The system will greatly reduce complications arising from misdiagnosis or wrong diagnosis of a number of health conditions. The epidemic alert system which monitors the different diagnosis of all doctors triggers an alert message to all the predefined relevant government agencies at any time the number of treated cases of a particular disease by different doctors for specific locations exceeds a threshold value. This will help to reduce the occurrence of epidemics and its associated negative consequences. A database of the prescription, diagnosis and the transcripts of the entire process are maintained and can be used when second opinions or expert advice is required for any patient.

\section{SYSTEM BENEFITS}

The benefits of this system are outlined below. 
1. It enables early and accurate diagnosis of ailments and facilitates the early commencement of appropriate treatment. Reports have shown that most terminal diseases are actually curable if detected early.

2. It facilitates rapid access to second opinions. This system will enable doctors to seek a second opinion for cases that require such. Both the visual and audio transcripts of the doctor patient interactions can be forwarded to different specialists located in different parts of the world at the same time for their opinion.

3. It enables a higher utilization factor of the government hospitals in the urban areas as more doctors can be employed and based in the urban areas to provide coverage to the rural areas.

4. It is cost effective in the sense that the sensors and the systems located at the rural areas are low cost resulting in a low total cost of ownership, low CAPEX and OPEX.

5. This system will reduce the effect of quackery as it will provide access to qualitative health care delivery to the rural dwellers

6. The epidemic alert will enable government manage cases of epidemics and contain it before it starts/spreads. The database generated by this system will help governments in proper planning of the health care delivery systems for the rural areas and also track other environmental issues as it affects the public health of the rural dwellers.

7. The doctors and onsite health center attendants require basic computer appreciation training to be able to utilize the system.

\section{CONCLUSION}

This system has the capability of improving the patients/doctor ratio for rural areas without the actual relocation of doctors to such areas. It also provides access for the rural dwellers to qualitative health care available in the urban centers without the cost and inconvenience of travel to urban hospitals. The limitation of bandwidth costs and transmission outages associated with this system can be reduced by the use of multiplexing/collation centers where traffic from a large number of health centers are collated and transmitted together using appropriate technologies. This will reduce the average transmission cost per center and the limitation of transmission outage can be mitigated by the use of suitable transmission frequencies which are resistant to rain attenuation and the use of automatic gain compensating networks which ensures that transmission is maintained regardless of the weather conditions.

\section{REFERENCES}

[1] K. Ojo, "The crisis in the distribution of health personnel in Nigeria" Health Policy And Planning, Vol. 5, No. 1, pp. 60-65, 1990

[2] M. Kamien, W. Cameron, "Solving the shortage of general practitioners in remote and rural Australia: a Sisyphean task", The Medical Journal of Australia, Vol. 185, No 11, pp. 652-653, 2006

[3] "Health care in India", www.wikipeadia.org/wiki/healthcare_in_India
[4] G. Kombe, S. Chankova, H. Nguyen, D. Chipanta, A. Onoja, K. Ogungbemi, A. Taye, "Confronting HIV/AIDS, TB, and Malaria: a situation analysis of human resources health in Nigeria: emerging challenges and opportunities", Health Systems 20/20, USAID 2007

[5] I. A. Adeoye, M. D. Dairo, L. V. Adekunle, H. O. Adedokun, J. Makanjuola, "Investigation of measles outbreak in a rural Nigeria community - The Aladura experience", African Journal of Microbiology Research, Vol. 4, No. 5, pp. 360-366, 2010

[6] I. H. Kara, A. Ceylon, H. Acemoglu, "Measles epidemic in Turkey and developing countries: review of the literature", Middle East Journal of Family Medicine, Vol. 5, No. 5, 2004.

[7] F. J. Spenser, "Epidemic Shigellosis in a rural area", Public Health Reports, Vol. 76, No. 3, pp. 219-222, 1961

[8] World Health Organization Media Center, "African Trypanosomiasis or sleeping sickness", http://www.who.int/mediacentre/factsheets/fs259/en/

[9] World Health Organization, "WHO supports malaria epidemic prevention and control in Pakistan", www.who.int/entity/hac/crises/pak/releases/12october2010

[10] A. M. Prentice, "The emerging epidemic of obesity in developing countries", International Journal of Epidemiology, Vol. 35, No. 1, pp. 93-99, 2005

[11] D. Smith, "Cholera kills more than 1500 people in Nigeria", The Guardian, $26^{\text {th }}$ October, 2010

[12] United Nations Institute for training and research. Briefing report. UNITAR/UNFPA/IOM, Key migration issues workshop series: New York. 2006, available at: www.un.org/esa/population/meetings/fourthcoord2005/P06_UNITAR.p df

[13] World Health Organization. "The global shortage of health workers and its input". Fact sheet No. 302, 2006

[14] United Nations Population Facts, "Health workers, international migration and development", No. 2010/2/E/Rev, 2010, available at: http://www.un.org/esa/population/publications/popfacts/popfacts_20102rev.pdf

[15] S. Ouma, M. E. Herselman. "E-health in rural areas: case of developing countries", International Journal of Biological and Life Sciences, Vol. 4, No. 4, pp. 194-200, 2008

[16] H. K. Sellapan, L. Sacks, "Intelligent Dropping scenario for motion JPEG2000 Transmission over satellite networks", available at: http://www.ee.ucl.ac.uk/lcs/previous/LCS2005/23.pdf

[17] S. Dogan, A. H. Sadka, A. M. Kondoz, "Video transmission over mobile satellite systems", International Journal of Satellite Communications, Vol. 18, pp. 185-205, 2000.

[18] L. Patil, Video Transmission over varying bandwidth links. M.Tech Desertation. Indian Institute of Technology Bombay, 2006, availablr at: www.it.iitb.ac.in/ sri/students/laxmikant-thesis.pdf.

[19] ETSI Final draft EN 302307 (v1.1.1) Digital Video Broadcasting (DVB) Second generation framing structure, channel coding and modulation systems for broadcasting interactive services, news gathering and other broadband satellite applications(DVB-S2). 2005. www.etsi.org

[20] Y. Mostovoy, "Maximizing Satellite Transmission Efficiency with DVB-S2", $\quad$ Scopus, available at: http://www.scopus.ru/files/Maximizing_Satellite_Transmission_Efficien cy_With_DVB-S2.pdf

[21] CODAN, "Introduction to digital microwave radio technology", available at: http://codan.ru/upload/File/codan/en/3p4.pdf

[22] Telecommunication handbook for transportation professionals: the basics of telecommunications, Final Report. US Department of Transportation, Federal Highway Administration, 2004.

[23] CISCO, "Stream Manager Video surveillance Solutions Reference Network design", CISCO Systems 2007. 